\title{
Anabases
}

ANABASES Traditions et réceptions de l'Antiquité

16 | 2012

Varia

\section{Homère, L'Iliade, traduit du grec par Philippe Brunet}

Cristina Noacco et Adeline Grand-Clément

\section{(2) OpenEdition}

\section{Journals}

Édition électronique

URL : http://journals.openedition.org/anabases/4023

DOI : 10.4000/anabases.4023

ISSN : 2256-9421

Éditeur

E.R.A.S.M.E.

\section{Édition imprimée}

Date de publication : 1 octobre 2012

Pagination : 311-314

ISSN : 1774-4296

\section{Référence électronique}

Cristina Noacco et Adeline Grand-Clément, « Homère, L'lliade, traduit du grec par Philippe Brunet », Anabases [En ligne], 16 | 2012, mis en ligne le 01 octobre 2012, consulté le 21 septembre 2020. URL: http://journals.openedition.org/anabases/4023 ; DOI : https://doi.org/10.4000/anabases.4023

Ce document a été généré automatiquement le 21 septembre 2020.

(c) Anabases 


\title{
Homère, L'Iliade, traduit du grec par Philippe Brunet
}

\author{
Cristina Noacco et Adeline Grand-Clément
}

\section{RÉFÉRENCE}

Homère, L'Iliade, traduit du grec par Philippe Brunet, préface, notes et répertoire établis par le traducteur, Paris, Éditions du Seuil, 2010, 560 p.

24 euros / ISBN 978-2-02-097887-3.

1 Proposer une nouvelle traduction française de l'Iliade : la tâche en soi est déjà énorme. Mais, disons-le d'emblée, l'ambition affichée par Philippe Brunet va au-delà : «Faire entendre quelque chose de la voix grecque » (p. 21), «faire circuler la parole épique » (p. 27). Et pour demeurer fidèle au «chatoiement poétique » d'Homère, l'auteur a tenu à « rendre l'hexamètre » employé par l'aède pour composer les épopées.

2 Le projet de Ph. Brunet est donc avant tout un défi lancé à la langue française. Il s'agit en effet d'une traduction isométrique de l'épopée grecque, c'est-à-dire d'une adaptation du rythme métrique de la langue d'Homère à la langue française. Elle est le fruit d'une riche expérience musicale personnelle et de vingt ans de recherches stylistiques, de lectures publiques et de performances théâtrales, visant à restituer la nature vocale, rythmique et expressive de l'hexamètre dactylique grec. Ce dernier répond à une règle de composition à la fois souple et précise : il se compose de six mesures, dont chacune est formée de trois syllabes (le dactyle, comportant une syllabe longue et deux brèves, qui occupe notamment toujours la cinquième position) ou de deux syllabes (le spondée, fait de deux syllabes longues, qu'on retrouve toujours en sixième position).

3 L'enjeu de la restitution de l'hexamètre homérique en français consiste à reconnaître comme indissoluble l'association, propre à l'épopée, de l'oralité et de l'écrit. L'auteur précise, dans la préface du livre, que le poème homérique requiert une lecture à haute voix destinée à faire revivre le rythme et la musicalité de l'hexamètre : il doit en aller 
de même dans la traduction. Ph. Brunet invite ainsi le lecteur à scander le français comme une langue accentuelle, marquée par des accents intensifs, et à lire les vers en faisant durer les voyelles qui constituent les temps forts de l'hexamètre. Par exemple, comme dans le vers homérique, la première syllabe, qu'elle «soit forte par nature ("Chante déesse »), ou non (« Le Péléide ») [...] doit être marquée par l'intensité, mais aussi par la hauteur, la durée, selon les proportions variables qui relèvent de l'art de dire le vers » (p. 22). Ph. Brunet cherche de la sorte à s'approcher des performances poétiques des aèdes grecs: "Le rythme, en grec ancien comme en latin et dans la transposition française, est imposé, régulé, ménagé par le récitant » (p. 24).

4 Le désir de rendre Homère en hexamètres n'est pas nouveau. Il voit le jour dès la Renaissance : les distiques de Jodelle et les chansons de Baïf représentent autant de tentatives de traduction de la poésie homérique en vers quantitatifs français. On sait aussi, d'après une lettre d'Agrippa d'Aubigné à Salomon Certon, qu'une traduction intégrale de l'Iliade avait été composée en hexamètres français par un certain Mousset. Le texte ne nous est cependant pas parvenu : la traduction de Philippe Brunet est donc à ce jour l'unique traduction isométrique de l'Iliade en français, entreprise qui a été couronnée par l'Académie française en 2011 (Prix de traduction Jules Janin). Elle s'inscrit dans une tendance européenne de traduction en hexamètres de l'Iliade qui a connu d'autres succès : la traduction en allemand de Johann-Heinrich Voss, le rival de Goethe, celle en russe de Nicolas Gneditch, ami de Pouchkine, les traductions en roumain de George Murnu et de Dan Slusanschi, ainsi que les récentes traductions de Rodney Merill en anglais et de Daniele Ventre en italien.

5 L'auteur explique le sens de sa démarche dans une longue préface (p. 7-31), suivie d'une « Note sur l'édition» (p. 33-34). Il insiste sur le statut qu'il accorde au texte homérique : l'Iliade n'est pas envisagée comme un récit, un texte figé dont il s'agirait d'étudier la structure narrative, mais bien comme un chant ouvert, celui d'Homère, auteur singulier d'une œuvre dont le souffle s'est trouvé démultiplié par les incessantes performances des aèdes. Partant, l'auteur prend clairement position dans le débat qui entoure la "question homérique». Selon lui, l'Iliade et l'Odyssée ne doivent pas être attribuées à une "tradition collective » informe et anonyme. Les deux poèmes auraient été composés avec art par un auteur unique, Homère, à la fois réceptacle et amplificateur d'une mémoire et d'une tradition orale millénaires. Pour étayer sa thèse, $\mathrm{Ph}$. Brunet souligne à plusieurs reprises les correspondances qui existent entre les deux poèmes. S'appuyant sur la thèse de $\mathrm{P}$. Fortassier (1998), il propose ainsi un tableau synoptique faisant apparaitre, par un jeu de miroir, les analogies qu'il a repérées, chant par chant, entre les épisodes de l'Iliade et ceux l'odyssée.

Comment l'auteur a-t-il établi la traduction? La méthode de travail qu'il a adoptée se caractérise par un certain nombre de choix d'ordre syntaxique, stylistique et herméneutique. Tout d'abord, l'auteur s'est attaché à restituer la structure syntaxique du récit en suivant, vers après vers, la structure métrique de l'Iliade, tout en assurant la fluidité du récit, qui le rend accessible au plus large public. Ph. Brunet est également fidèle au style du texte homérique et il prend soin de le transposer « naturellement » en français. Ainsi, dans la traduction de l'Iliade, comme dans son modèle grec, on trouve des répétitions ( «si j'ai jamais, Sminthée, couvert ton temple splendide, / si j’ai jamais grillé pour toi des cuisses luisantes », I, 39-40), des allitérations (en m, par ex. : « Mais toi, fais-moi, par serment, la promesse ", I, 76), le rythme coupé (avec un enjambement: «Il tut, se leva, mit une coupe à deux anses / entre les mains de sa 
mère... », I, 584-585) ou lent («La messagère Iris vint trouver Hélène aux mains blanches ", III, 121), des énumérations (le catalogue des vaisseaux, II) etc. Les notes de bas de page sont, elles, réduites à l'essentiel. Elles n'abordent pas des questions d'ordre philologique, comme c'est le cas dans les éditions érudites des textes anciens, mais offrent au lecteur les éléments nécessaires à l'identification de tel ou tel personnage ou signalent les parallèles qui existent avec d'autres vers de l'Iliade, ou avec un épisode analogue raconté dans l'Odyssée - fournissant une orientation nouvelle et originale sur les poèmes homériques.

7 La nouvelle traduction de $\mathrm{Ph}$. Brunet vient utilement compléter l'édition bilingue de la C.U.F. («collection Budé») des Belles Lettres, qui sert de référence au lecteur francophone. Réalisée par Paul Mazon en 1937-1938, avec la collaboration de P. Chantraine, $\mathrm{P}$. Collart et $\mathrm{R}$. Langumier, elle a été régulièrement rééditée depuis, et a aussi paru en format de poche (en trois volumes). Mais cette traduction en prose, soucieuse de «coller » au texte grec, ne cherche pas à rendre la musicalité du chant de l'aède. L'initiative de $\mathrm{Ph}$. Brunet comble donc ce manque, et constitue en cela le pendant de la traduction «syllabique » de l'Odyssée réalisée par le poète $\mathrm{Ph}$. Jaccottet en 1955 et rééditée en 1982. Il s'agit dans les deux cas de privilégier le rythme et la poésie du texte : les considérations philologiques ne priment pas sur les exigences du mètre. Pour autant, les libertés prises par Ph. Brunet dans sa traduction ne s'apparentent pas à des trahisons. L'auteur s'appuie sur une grande sensibilité et une réelle familiarité visà-vis du grec ancien, dont il parvient à rendre les subtilités. Il s'autorise aussi des variations dans la manière de rendre un même adjectif, de façon à s'adapter au rythme du vers. En procédant de la sorte, il rejoint la manière dont ont été composées les épopées homériques. Bien sûr, l'helléniste et le philologue regretteront l'absence totale du texte grec - y compris dans les notes de bas de page - qui aurait permis de comparer la version originale et la traduction, afin de repérer les écarts éventuels. Mais l'auteur précise qu'il a procédé à sa propre édition du texte et annonce qu'elle devrait être consultable sur internet (http://www.homeros.fr).

8 À l'évidence, Ph. Brunet a pour ambition de faire résonner la voix homérique auprès d'un large public - une version revue en format de poche est déjà en préparation. Comme la traduction de $\mathrm{Ph}$. Jaccottet, elle a ceci d'utile qu'elle permet de rassembler en un seul volume les vingt-quatre chants de l'Iliade, la rendant accessible au néophyte et à l'amateur. Le souci pédagogique et le désir d'ouverture qui animent l'auteur se perçoivent d'ailleurs dans les choix de présentation du texte. Chacun des vingt-quatre chants est gratifié d'un titre, qui en présente le thème porteur, ainsi que d'une brève introduction qui en résume l'intrigue. Un découpage interne est également proposé : l'auteur a donné des titres aux principales séquences, de manière à faciliter l'orientation du lecteur. Un utile " répertoire des noms et des épithètes remarquables » (p.523-558) clôt le volume, donnant des repères essentiels pour l'identification des personnages, avec renvoi aux passages où ils apparaissent et mention des principales épithètes utilisées par Homère pour les qualifier. On pourra peut-être regretter de ne trouver aucune bibliographie à la fin : l'auteur s'en explique dans la préface et renvoie le lecteur à quelques sites internet utiles.

9 Assurément, cette version de l'Iliade en vers français représente un jalon important dans la réception du texte homérique. C'est plus qu'une simple traduction : il s'agit d'une transposition, réalisée dans la tradition des anciens aèdes. Le principal apport de l'auteur consiste à mettre à profit son expérience musicale et théâtrale. Cette 
expérience polymorphe nourrit une approche originale et féconde, mise au service d'un pari audacieux («laisser Homère exister »), qui semble atteint. Il n'est pas anodin, d'ailleurs, que Ph. Brunet ait dédié ce volume aux enfants, « aux futurs aèdes » (p. 27) : il dévoile par là son ambition de mettre à l'honneur l'oralité. Il a conscience du risque induit par une édition imprimée, qui pourrait figer l'élan poétique. Ainsi, comme l'enfant qu'il évoque dans l'exergue de sa préface, il se dit prêt à renverser, du moins symboliquement, le château de sable qu'il a patiemment construit sur la plage.

\section{AUTEURS}

\section{CRISTINA NOACCO}

Université de Toulouse (UTM)

cnoacco@yahoo.fr

\section{ADELINE GRAND-CLÉMENT}

Université de Toulouse (UTM)

adelinegc@yahoo.fr 